\title{
Impact of the mandatory age-based single-embryo transfer legislation in Turkey on outcome of in vitro fertilization: a multicentre study
}

\author{
B. Ergun, ${ }^{7}$ E. Bastu, ${ }^{7}$ R. Galandarov, ${ }^{1}$ G. Koksal, ${ }^{1}$ H. Yumru' and E. Attar ${ }^{1}$
}

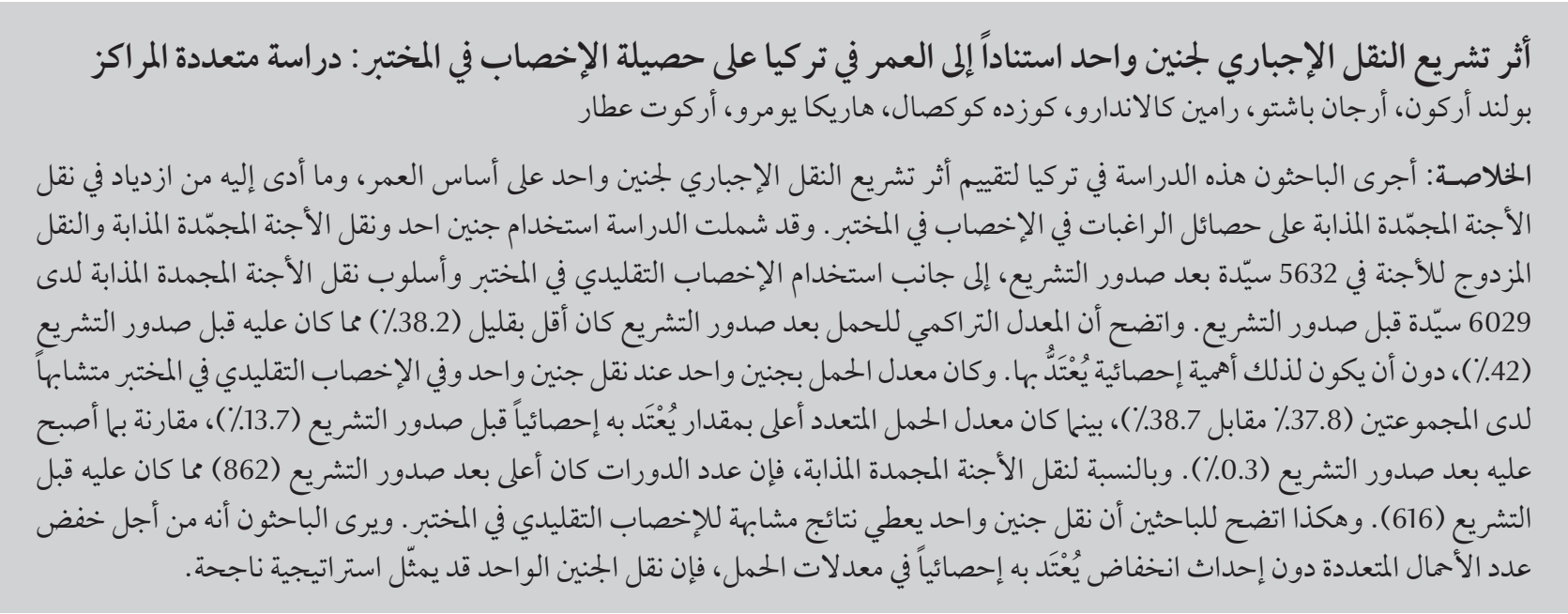

ABSTRACT This study in Turkey evaluated the impact of age-based mandatory single-embryo transfer (SET) legislation with the subsequent increase in frozen-thawed embryo transfer (FT-ET) on pregnancy outcome of in vitro fertilization (IVF) patients. SET, FT-ET and double-embryo transfer were used in 5632 patients after legislation, while traditional IVF and FT-ET approach was used in 6029 patients before legislation. The cumulative pregnancy rate after legislation was slightly lower (38.2\%) than before legislation (42.0\%) but not significantly so. The single pregnancy rate for SET and traditional IVF were similar between the 2 groups (37.8\% versus $28.7 \%$ ), while multiple pregnancy rates were significantly higher before than after legislation (13.7\% versus $0.3 \%)$. For FT-ET, the number of cycles was significantly higher after legislation (862 versus 616). SET yielded similar results to traditional IVF. In order to reduce multiple pregnancies without significantly decreasing pregnancy rates, SET might be a successful strategy.

Impact de la loi turque rendant obligatoire le transfert d'un embryon unique en fonction de l'âge sur l'issue de la fécondation in vitro : étude multicentrique

RÉSUMÉ La présente étude menée en Turquie a évalué l'impact de la loi rendant obligatoire le transfert d'un embryon unique en fonction de l'âge et de l'augmentation consécutive des transferts d'embryons congelésdécongelés sur l'issue de la grossesse des patientes bénéficiant d'une fécondation in vitro. Le transfert d'un embryon unique, le transfert d'embryons congelés-décongelés et le transfert de deux embryons ont été réalisés chez 5632 patientes après l'entrée en vigueur de la loi, tandis que l'approche traditionnelle par fécondation in vitro et par transferts d'embryons congelés-décongelés a été utilisée chez 6029 patientes avant le vote de cette loi. Le taux de grossesses cumulé après l'application de la nouvelle loi était légèrement inférieur (38,2\%) au taux avant la nouvelle loi (42\%), mais la différence n'était pas très importante. Les taux de grossesses simples par transfert d'un embryon unique et par fécondation in vitro traditionnelle étaient similaires entre les deux groupes (37,8\% contre $28,7 \%)$, tandis que les taux de grossesses multiples étaient significativement supérieurs avant l'application de la loi (13,7 \% contre 0,3\%). Pour le transfert d'embryons congelés-décongelés, le nombre de cycles était nettement supérieur après la nouvelle loi (862 contre 616). Le transfert d'un embryon unique a généré des résultats similaires à la fécondation in vitro. Afin de réduire le nombre de grossesses multiples sans réduire le taux de grossesses de manière significative, la politique du transfert d'un embryon unique peut représenter une stratégie efficace. 


\section{Introduction}

Since the success of the first in vitro fertilization (IVF) birth in 1978, IVF became a source of hope for many infertile couples around the world. To increase the success rates of pregnan$c y$, for many years multiple embryo transfers were preferred. However, during recent decades, the multiple pregnancy rate, especially the twin pregnancy rate, has been increasing as a result of assisted reproduction technologies $[1,2]$. Multiple pregnancies are the most common complication associated with IVF treatment. It is not only a financial, medical and ethical burden on couples, it is considered a high-risk pregnancy for both the mother and infants, due to the relative increased incidence of maternal, perinatal and neonatal morbidity and mortality [1-5]. Between 2005 and 2006 in Europe 19.9\% of IVF live births were still twins, while the natural incidence was $1 \%-1.5 \%$ when conceived spontaneously $[3,4]$. This is important for infertility specialists and also for obstetricians, neonatologists and primary health care providers due to the risks involved and the increased costs to the health service.

The most successful way to decrease twin pregnancies in IVF is to transfer only 1 embryo [6]. The singleembryo transfer (SET) approach is becoming more viable, and several randomized studies have been performed in which transfer of a single embryo was compared with the transfer of 2 embryos [7]. Yet health care commissioners in several countries do not know exactly how alternative embryo transfer strategies will affect health service costs, pregnancy rates and twin pregnancy rates over time in different subgroups of women [5]. Because of the risks mentioned above, in March 2010 the Turkish Ministry of Health legislated to make SET mandatory (for the first 2 IVF cycles) for women in Turkey who are aged 35 years and younger. For women who are older than 35 years, double-embryo transfer (DET) is permitted in all IVF cycles. After 2 failed IVF cycles, regardless of age, DET is permitted. In all cases, if additional good-quality embryos are available, they can be frozen and used in the future.

The aim of this study was to evaluate the impact of this age-based mandatory legislation on pregnancy outcomes, regardless of medical history or the etiology of IVF (male factor, ovulatory factor, infertility duration, etc.).

\section{Methods}

The Department of Obstetrics and Gynaecology at Istanbul University School of Medicine coordinated this multicentre, retrospective study, in which the results of 7 IVF centres in Turkey were included.

\section{Sample}

Group 1 included IVF patients from the year before the aforementioned mandatory legislation (6029 patients, treated between March 2009 and February 2010). During this period, patients (regardless of age) received a maximum number of 3 high-quality embryos. The clinician on a case-bycase approach decided the exact number of transferred embryos.

Group 2 included IVF patients treated after the March 2010 mandatory legislation (5632 patients, treated between March 2010 and February 2011). Within group 2, patients $\leq$ 35 years old received only a single embryo in their first 2 IVF attempts regardless of their medical history, duration of infertility or ethology of infertility. Patients $\leq 35$ years old received a maximum number of 2 embryo transfers only when they had a history of 2 failed IVF cycles. Patients $>35$ years old received a maximum number of 2 embryo transfers regardless of their previous IVF failures, medical history, duration of infertility or ethology of infertility. The mandatory legislation mentioned above also involved frozen-thawed embryo transfers (FT$\mathrm{ET})$.

The age, demographic features and body mass index (BMI) were adjusted and matched for both groups. To achieve demographic standardization between the 2 groups, patients with extreme BMI $\left(<18\right.$ and $\left.>35 \mathrm{~kg} / \mathrm{m}^{2}\right)$ and/or age ( $<18$ and $>39$ years) were excluded from the study. In all the centres, only good-quality embryos were transferred. Good-quality embryos were defined by their morphologic features and included embryos with $<20 \%$ fragmentation and $4-6$ cells at day 2, 6 and 10 cells at day 3. In both groups, the numbers of single and multiple pregnancies and number of FT-ETs were recorded.

\section{Ovarian stimulation and IVF/ ICSI procedures}

Each centre was allowed to follow its own local stimulation protocol according to the medical history of the patient, including age and levels of antral follicle count, follicle-stimulating hormone and body mass index. Hence, ovarian stimulation was performed using an antagonist or agonist protocol. Stimulation was performed with recombinant follicle-stimulating hormone (Gonal-F, Serono, Puregon, Organon) or urinary-derived folliclestimulating hormone (Menopur, Ferring). Oocyte retrieval was performed via vaginal ultrasound guidance, 36 hours after human chorionic gonadotropin (hCG) administration. Fertilization was performed by standard intra-cytoplasmic sperm injection (ICSI) depending on the experience of each centre. Progesterone was administered intramuscularly or vaginally daily, from the time of oocyte retrieval until the time of a negative pregnancy test or until 2 weeks after a positive pregnancy test. 


\section{Embryo culture, transfer, cryopreservation and frozen embryo transfer}

Oocytes and embryos were cultured in a ready-to-use commercially available medium: IVF medium (Irvine Scientific). After micro-injection, oocytes were incubated for $14-16$ hours at $37^{\circ} \mathrm{C}$ and $5 \% \mathrm{CO}_{2}$ within an early cleavage medium. The embryos were transferred on the 2 nd or 3 rd day via ultrasound guidance. Embryo morphology was scored from grade 1 to 4 . Grade 1 embryos contained 6-8 blastomeres and did not have multi-nucleation or fragmentations. Cryopreservation of additional embryos was performed on the same day of the fresh embryo transfer, depending on their morphological aspect. Cryopreservation was performed on day 3 embryos. The criteria for cryopreservation of embryos were at least 7 or 8 cells, $>$ fragmentation $10 \%$ and no multinucleated blastomeres.

Each centre was allowed to follow its own FT-ET protocol as well. The same FT-ET protocol was applied in SET and DET groups in each centre.

\section{Outcomes}

Pregnancy was initially detected by rising serum hCG concentration in 2 consecutive assays at least 12 days after embryo transfer. The pregnancy was defined as clinical if fetal cardiac activity was visualized by ultrasonography in the 7th week of gestation. The clinical pregnancy rate was calculated as the ratio between the number of pregnancies after fresh embryo transfers and the number of oocyte pick-ups.

\section{Statistical analysis}

All data were analysed with the use of the SPSS for Windows software, version 16.0. Data are presented as means and standard deviation (SD) or percentages The Shapiro-Wilk Wtest was used to identify whether the variables were normally distributed. The differences between groups were assessed by using unpaired $t$-tests for parametric data and Mann-Whitney U-test for nonparametric data. Statistical significance was defined as $P<0.05$.

\section{Results}

An overview of the groups is presented in Table 1. The total pregnancy rate in group 2 (after legislation) (38.2\%) was slightly lower than for group 1 (before legislation) $(42.0 \%)$, but this difference was not statistically significant $(P$ $>0.05$ ). Single pregnancy rates were $37.8 \%$ for SET in group 2 and $28.7 \%$ for traditional IVF in group 1 . The multiple pregnancy rate was significantly lower for SET in group $2(0.3 \%)$ than for traditional IVF in group $1(13.7 \%)(P$ $<0.05$ )

As far as FT-ET was concerned, the proportion of transfers was significantly higher in group $2(862 / 5632,15.3 \%)$ than group $1(616 / 6029,10.2 \%)$ $(P<0.05)$. There was no significant difference in the number of FT-ET single pregnancies comparing group $2(28.0 \%)$ and group 1 (25.4\%) $(P>$ $0.05)$. However, there was a decrease in the number of multiple pregnancies as a result of FT-ET in group 2 (4.9\%) and group $1(14.4 \%)(P<0.05)$.

\begin{tabular}{|c|c|c|c|c|c|c|c|c|c|}
\hline $\begin{array}{l}\text { Table } 1 \text { Preg } \\
\text { undergoing } \\
\text { legislation) }\end{array}$ & $\begin{array}{l}\text { (based o } \\
\text { lization }\end{array}$ & $\begin{array}{l}\text { ositive } \\
\text { roup }\end{array}$ & $\begin{array}{l}\text { hum } \\
\text { re er }\end{array}$ & $\begin{array}{l}\text { orion } \\
\text {-tran }\end{array}$ & $\begin{array}{l}\text { idotro } \\
\text { islatio }\end{array}$ & $\begin{array}{l}\text { or fetc } \\
\text { and grc }\end{array}$ & $\begin{array}{l}\text { ac activi } \\
\text { after em }\end{array}$ & $\begin{array}{l}\text { in wo } \\
\text { o-trar }\end{array}$ & \\
\hline Groups & No. of & & & & Iancy ra & (per tra & & & \\
\hline & patients & $\beta-H C$ & itive & & cardiac & ctivity pc & & & \\
\hline & & & & Single & Iancies & Multipl & nancies & & \\
\hline & & No. & $\%$ & No. & $\%$ & No. & $\%$ & No. & $\%$ \\
\hline Fresh embry & & & & & & & & & \\
\hline Group 1 & 5413 & 2577 & 47.6 & 1552 & $28.7^{\mathrm{a}}$ & 740 & $13.7^{c}$ & - & - \\
\hline Group 2: & & & & & & & & & \\
\hline SET & 2997 & 1349 & 45.0 & 1134 & $37.8^{\mathrm{a}}$ & 10 & $0.3^{c}$ & - & - \\
\hline DET & 1773 & 809 & 45.6 & 536 & 30.2 & 190 & 10.7 & - & - \\
\hline$F T-E T$ & & & & & & & & & \\
\hline Group 1 & 616 & 322 & 52.2 & 157 & $25.4^{\mathrm{b}}$ & 89 & $14.4^{\mathrm{d}}$ & - & - \\
\hline Group 2 & 862 & 396 & 45.9 & 242 & $28.0^{\mathrm{b}}$ & 43 & $4.9^{d}$ & - & - \\
\hline Total & & & & & & & & & \\
\hline Group 1 & 6029 & - & - & 1709 & 28.3 & 829 & 13.7 & 2538 & 42.0 \\
\hline Group 2 & 5632 & - & - & 1912 & 33.9 & 243 & 4.3 & 2155 & 38.2 \\
\hline
\end{tabular}

${ }^{a} P>0.05$ group 1 traditional IVF versus group 2 SET; ${ }^{b} P>0.05$ FT-ET group 1 FT-ET versus group 2 FT-ET; $P<0.05$ group 1 traditional IVF versUS group 2 SET; ${ }^{d} P<0.05$ group 1 FT-ET versus group 2 FT-ET.

$F T-E T=$ frozen-thawed embryo transfer; $S E T=$ single-embryo transfer; $D E T=$ double-embryo transfer; $I V F=$ in vitro fertilization; $\beta$ - $H C G=$ beta human chorionic gonadotropin. 


\begin{tabular}{|c|c|c|c|c|c|}
\hline \multicolumn{6}{|c|}{$\begin{array}{l}\text { Table } 2 \text { Pregnancy rates of fresh embryo } \\
\text { activity) in women undergoing in vitro fe } \\
\text { embryo-transfer legislation) }\end{array}$} \\
\hline \multirow[t]{3}{*}{ Groups } & \multirow{3}{*}{$\begin{array}{l}\text { No. of embryo } \\
\text { transfers }\end{array}$} & \multicolumn{4}{|c|}{ Pregnancy rate } \\
\hline & & \multicolumn{2}{|c|}{$\begin{array}{c}\beta \text {-HCG positive } \\
\text { (embryo transfers per cycle) }\end{array}$} & \multicolumn{2}{|c|}{$\begin{array}{l}\text { Fetal cardiac activity positive } \\
\text { (embryo transfers per cycle) }\end{array}$} \\
\hline & & No. & $\%(95 \% \mathrm{Cl})$ & No. & $\%(95 \% \mathrm{Cl})$ \\
\hline Group 1 & 5413 & 2577 & $47.6^{a}(36.5-52.4)$ & 2292 & $42.9^{\mathrm{a}}(31.2-48.3)$ \\
\hline \multicolumn{6}{|l|}{ Group 2} \\
\hline SET & 2997 & 1349 & $45.1(32.4-51.6)$ & 1144 & $38.2(28.1-47.5)$ \\
\hline DET & 1773 & 809 & $45.6(29.2-39.8)$ & 726 & $40.9(30.3-44.5)$ \\
\hline Total & 4770 & 2158 & $45.2^{\mathrm{a}}(37.3-61.2)$ & 1870 & $39.2^{\mathrm{a}}(29.8-46.4)$ \\
\hline
\end{tabular}

${ }^{a} P>0.05$ SET and DET group 2 versus traditional IVF group 1.

$S E T=$ single-embryo transfer $; D E T=$ double-embryo transfer $; \beta-H C G=$ beta human chorionic gonadotropin; $C l=$ confidence interval .

When successful pregnancy outcome of only fresh embryo transfers were compared between SET and DET in group 2 (after legislation) and traditional IVF in group 1 (before legislation), the differences were non-significant ( $\beta$-HCG positive rate: $45.2 \%$ versus $47.6 \%$, clinical pregnancy rate: $39.2 \%$ versus $42.9 \%)(P>0.05)$ (Table 2).

When we divided group 2 into SET and DET subgroups, $\beta$-HCG positive and clinical pregnancy success rates of only fresh-embryo transfers showed no statistically significant difference ( $\beta$-HCG positive rate: $45.1 \%$ versus $45.6 \%$, clinical pregnancy rate: $38.2 \%$ versus $40.9 \%)(P>0.05)$ (Table 2$)$.

Comparison of single and multiple pregnancies of fresh embryo transfer on SET and DET in group 2 indicated a significant increase in the DET subgroup (clinical pregnancy rate: $0.9 \%$ versus $26.2 \%)(P<0.05)($ Table 3$)$.

\section{Discussion}

In this large, retrospective, multi-centre study, transferring 1 fresh embryo according to the age-based mandatory legislation did not result in a substantially lower rate of pregnancies than transferring embryos according to the decision of the clinician before the legislation. In addition, the use of SET resulted in a significant reduction in the rate of multiple pregnancies.

SET is effective in reducing the rate of twin pregnancies following IVF. In 6 published randomized controlled trails comparing SET with DET, rates of multiple pregnancies were significantly lower after SET [8-14]. Six of these trials were conducted using predominantly cleavage-stage embryos, those cultured in vitro for 2 or 3 days. A Cochrane review including 4 of these trials found an odds ratio of 23.55 (95\% CI 8.00-69.29) for multiple pregnancy following DET compared with SET [15].

A French study demonstrated that a high cumulative clinical pregnancy rate (69.8\%) and delivery rate (54.7\%) could be obtained after a single oocyte pick-up and the transfer of only 1 fresh embryo [16]. These results were not lower than the cumulative pregnancy rate $(64.3 \%)$ and delivery rate $(49.0 \%)$ observed when 2 fresh embryos were transferred after IVF and ICSI in a similar population with the same embryo quality, in routine clinical practice. Their results can encourage IVF teams to routinely practise SET in selected populations and should increase the percentage of patients in favour of SET, which was only $35.0 \%$ in their study. Infertility specialists should also correctly inform patients about the realistic chances of obtaining a child after SET and on the incidence of potential

\begin{tabular}{|c|c|c|c|c|c|}
\hline \multirow[t]{3}{*}{ Groups } & \multirow{3}{*}{$\begin{array}{l}\text { No. of clinical } \\
\text { pregnancies }\end{array}$} & \multicolumn{4}{|c|}{ Pregnancy rate } \\
\hline & & \multicolumn{2}{|c|}{$\begin{array}{l}\text { Single pregnancies } \\
\text { (per clinical pregnancy) }\end{array}$} & \multicolumn{2}{|c|}{$\begin{array}{l}\text { Multiple pregnancies } \\
\text { (per clinical pregnancy) }\end{array}$} \\
\hline & & No. & $\%(95 \% \mathrm{Cl})$ & No. & $\%(95 \% \mathrm{Cl})$ \\
\hline \multicolumn{6}{|l|}{ Group 2} \\
\hline SET & 1144 & 1134 & $99.1^{\mathrm{a}}(0-5.1)$ & 10 & $0.9^{\mathrm{a}}(0-4.8)$ \\
\hline DET & 726 & 536 & $73.8^{\mathrm{a}}(17.3-31.2)$ & 190 & $26.2^{\mathrm{a}}(23.4-41.2)$ \\
\hline
\end{tabular}

${ }^{a} P<0.05$ SET group 2 versus DET group 2.

$S E T=$ single-embryo transfer; $D E T=$ double-embryo transfer; $C I=$ confidence interval. 
unfavourable effects of twin deliveries after DET. The introduction of SET has substantially reduced this risk $[12,17]$.

A Finnish study reported similar results for SET and DET for women aged 36-39 years, indicating that SET may also be applied in this age group [18]. Thus, SET could be recommended for women up to 39 years old. It also seems that the embryo quality is an important factor to be considered. Moreover, a number of studies underlined the importance of the whole embryo cohort quality, showing that the availability of several embryos of good quality was associated with higher implantation and pregnancy rates [19-21]. In addition, in another study, cumulative multiple live birth rates were significantly lower in the SET compared with the DET group [22].

A systematic review and metaanalysis of 6 randomized controlled trials comparing SET with DET of cleavage stage embryos published by Gelbaya et al. revealed cumulative multiple birth rates (CLBRs) that ranged from $35.8-46.3 \%$ but showed no statistically significant difference between the 2 groups [23]. Moreover, CLBRs decreased significantly from a range of $13.1 \%-41.2 \%$ in the DET group to $0 \%-0.8 \%$ in the SET group. In general, CLBRs following IVF has been reported as between $45 \%$ and $55 \%$. Maternal age has been shown to reduce these rates significantly, as has preimplantation genetic diagnosis. On the contrary, techniques mostly used to decrease the chance of multiple births, such as elective SET and traditional IVF, do not affect CLBRs while achieving a significant reduction in the rates of multiple pregnancy [24].

A potential hindrance to the use of SET is the patient's concern that the chance of pregnancy will be reduced. On the other hand, a change in attitude among patients may be possible with proper patient consultation. SET can be more easily accepted when there is insurance coverage for IVF. If patients pay for IVF, they might prefer more embryo transfers to maximize their chance of having a child. In Turkey, the social insurance covers up to 2 IVF cycles. Therefore, many patients want more than 1 embryo transfer to increase their chances. This factor usually results in discordance between the patient's wishes and clinician's legal responsibility. Moreover, in Turkey FT-ET is not covered separately by the social insurance (it is a part of the patient's 2 IVF cycle coverage). Our study findings suggest that FT-ET following an unsuccessful SET attempt yields similar pregnancy outcomes to fresh embryo transfer, while helping to keep multiple pregnancy incidence low, as indicated in a recent opinion review of reproductive medicine societies [25]. Hence, a separate social/ private insurance coverage for FT-ET may be considered to increase the support to SET.

Finally, this study has some inherent limitations. As stated previously, patients generally have a strong belief that transferring more embryos will improve their probability of pregnancy despitethe well-recognized risks associated with twin deliveries. Hence, before the age-based mandatory legislation, statistically significant prospective studies to compare SET and DET were difficult to design in Turkey. Therefore, with this study we mainly tried to evaluate the impact of the age-based mandatory legislation of SET.

\section{Conclusions}

This multi-centre study clearly highlights that the SET strategy achieves pregnancy rates that were no lower than the rates after transfer of 2 fresh embryos. These optimistic results may influence the decision of eligible couples around the world in favour of SET along with the FT-ET option. In addition, it may convince practitioners of the necessity to apply carefully structured embryo transfer legislation at least in a well-selected population of patients.

\section{Acknowledgements}

We are indebted to Kadir Savan MD, Serkan Oral MD, Yucel Karaman MD, Semra Kahraman MD, Zafer Candan MD, Hakan Yelke MD, Aret Kamer MD, Faruk Bener MD, Hakan Ozornek MD, Teksen Camlibel MD and Melike Batukan MD for their recruitment of patients and collection of data.

\section{Funding: None.}

Competing interests: None declared.

\section{References}

1. Andersen AN et al. European IVF-monitoring programme (EIM), European Society of Human Reproduction and Embryology (ESHRE). Assisted reproductive technology in Europe, 2001. Results generated from European registers by ESHRE. Human Reproduction, 2005, 20:1158-1176.

2. Land JA, Evers JL. Risks and complications in assisted reproduction techniques: Report of an ESHRE consensus meeting. Human Reproduction, 2003, 18:455-457.
3. De Mouzon J et al. Assisted reproductive technology and intrauterine inseminations in Europe, 2006: results generated from European registers by ESHRE. Human Reproduction, 2010, 25:1851-1862.

4. Bortolus R et al. The epidemiology of multiple births. Human Reproduction Update, 1999, 5:179-187.

5. Scotland GS et al. Minimising twins in in vitro fertilisation: a modelling study assessing the costs, consequences and cost- 
utility of elective single versus double-embryo transfer over a 20-year time horizon. British Journal of Obstetrics and Gynaecology, 2011, 118:1073-1083.

6. Gerris JM. Single-embryo transfer and IVF/ICSI outcome: a balanced appraisal. Human Reproduction Update, 2005 11:105-121.

7. Fiddelers AA et al. Economic evaluations of single-versus double-embryo transfer in IVF. Human Reproduction Update, 2007, 13:5-13.

8. Gerris J et al. Prevention of twin pregnancy after in-vitro fertilization or intracytoplasmic sperm injection based on strict embryo criteria: a prospective randomized clinical trial. Human Reproduction, 1999, 14:2581-2587.

9. Martikainen $\mathrm{H}$ et al.Finnish ET Study Group. One versus two embryo transfer after IVF and ICSI: a randomized study. Human Reproduction, 2001, 16:1900-1903.

10. Lukassen HG et al. Two cycles with single-embryo transfer versus one cycle with double-embryo transfer: a randomized controlled trial. Human Reproduction, 2005, 20:702-708.

11. Gardner DK et al. Single blastocyst transfer: a prospective randomized trial. Fertility and Sterility, 2004, 81:551-555.

12. Thurin A et al. Elective single-embryo transfer versus doubleembryo transfer in in vitro fertilization. New England Journal of Medicine, 2004, 351:2392-2402.

13. van Montfoort AP et al. In unselected patients, elective singleembryo transfer prevents all multiples, but results in significantly lower pregnancy rates compared with double-embryo transfer: a randomized controlled trial. Human Reproduction, 2006, 21:338-343.

14. Moustafa MK, Sheded SA, El Aziz Mousta MA. Elective singleembryo transfer versus double-embryo transfer in assisted reproduction. Reproductive Biomedicine Online, 2008, 17:82-87.

15. Pandian Z et al. Number of embryos for transfer after IVF and ICSI: a Cochrane review. Human Reproduction, 2005, 20:2681-2687
16. Fauque $\mathbf{P}$ et al. Cumulative results including obstetrical and neonatal outcome of fresh and frozen-thawed cycles in elective single versus double fresh embryo transfers. Fertility and Sterility, 2010, 94:927-935.

17. Pandian $Z$ et al. Number of embryos for transfer following in-vitro fertilisation or intra-cytoplasmic sperm injection. Cochrane Database of Systematic Reviews, 2009, 15:CD003416.

18. Veleva $Z$ et al. Elective single-embryo transfer in women aged 36-39 years. Human Reproduction, 2006, 21:2098-2102.

19. Urman B et al. Outcome of blastocyst transfer according to availability of excess blastocysts suitable for cryopreservation. Reproductive Biomedicine Online, 2003, 7:587-592.

20. Devreker $\mathrm{F}$ et al. Comparison of two elective transfer policies of two embryos to reduce multiple pregnancies without impairing pregnancy rates. Human Reproduction, 1999, 14:83-89.

21. Balaban B et al. Blastocyst quality affects the success of blastocyst-stage embryo transfer. Fertility and Sterility, 2000, 74:282287.

22. Bechoua $S$ et al. How to demonstrate that eSET does not compromise the likelihood of having a baby? Human Reproduction, 2009, 24:3073-3081.

23. Gelbaya TA, Tsoumpou I, Nardo LG. The likelihood of live birth and multiple birth after single versus double-embryo transfer at the cleavage stage: a systematic review and meta-analysis. Fertility and Sterility, 2010, 94:936-945.

24. Moragianni VA, Penzias AS. Cumulative live-birth rates after assisted reproductive technology. Current Opinion in Obstetrics and Gynecology, 2010, 22:189-192.

25. Practice Committee of Society for Assisted Reproductive TechnologyPractice Committee of American Society for Reproductive Medicine. Elective single-embryo transfer. Fertility and Sterility, 2012, 97:835-842. 